\title{
A orientação externa da indústria de transformação brasileira após a liberalização comercial
}

\author{
The external orientation of the Brazilian manufacturing \\ industry after trade liberalization
}

\author{
RENATO FONSECA* \\ MÁRIO C. DE CARVALHO Jr. ** \\ HENRY POURCHET $* *$
}

RESUMO: Neste artigo, construímos indicadores de orientação externa para a indústria manufatureira brasileira. Esses indicadores nos permitem entender melhor as mudanças na orientação comercial durante os anos 90 e o efeito de um choque externo, considerando os canais de receita (vendas externas e concorrência doméstica com importações) e o custo (insumos importados). O estudo mostra que o coeficiente líquido de orientação externa para o setor manufatureiro como um todo caiu $11,3 \%$ entre 1989 e 1998, diminuindo o efeito positivo que a desvalorização da moeda teria no setor manufatureiro.

PALAVRAS-CHAVE: Integração comercial; exportações; liberalização; indicadores de orientação externa.

ABSTRACT: In this article we built external orientation indicators for the Brazilian manufacturing industry. These indicators allow us to better understand the changes on trade orientation during the 1990s and the effect of an external shock, considering both the revenue (external sales and domestic competition with imports) and the cost (imported inputs) channels. The study shows that the net external orientation coefficient for the manufacturing sector as a whole dropped by $11.3 \%$ between 1989 and 1998, diminishing the positive effect that currency devaluation would have on the manufacturing sector.

KEYWORDS: Commercial integration; exports; liberalization; external orientation indicators.

JEL Classification: F14; F60.

\footnotetext{
* Economista da CNI e Professor do Departamento de Economia da PUC-RJ.rfonseca@cni.org..

** Pesquisador da FUNCEX e Professor da FAF/UERJ..

*** Pesquisador da FUNCEX henrip@funcex.com.br .
} 


\section{INTRODUÇÃO}

Desde o início da década de 90 vem se assistindo a uma gradual mudança na orientação externa da economia brasileira. Durante este período transita-se de um regime de comércio fechado para um aberto em decorrência da política de liberalização comercial iniciada em 1990. O processo de abertura comercial teve como objetivo promover a modernização da indústria brasileira, que seria estimulada via competição com os produtores estrangeiros. Como pode ser visto em Fonseca (1996) e Hay (1997), este processo impulsionou uma série de mudanças profundas em prol da modernização da indústria brasileira. No entanto, passada quase uma década, a economia brasileira continua relativamente fechada ao comércio internacional.

Em 1989, as exportações brasileiras responderam por 8,3\% do PIB. Nove anos depois, esta participação caiu para $6,6 \%$, passando por 9,2\% em 1992. Mesmo a justando-se para o efeito da sobrevalorização do dólar que se seguiu ao Plano Real, podemos afirmar que o coeficiente de exportação da economia brasileira mantevese praticamente inalterado entre 1989 e 1998 . Como forma de ilustrar o baixo grau de abertura da economia brasileira, note-se que o coeficiente de exportação dos países europeus é de cerca de 30. Na Ásia e na América Latina o coeficiente médio é de, respectivamente, 36 e 15.

Os coeficientes de exportação e importação têm sido extensivamente utilizados como medidas de abertura econômica na literatura de comércio exterior. Especificamente para o caso brasileiro, há dois estudos recentes sobre o assunto que estimam indicadores de abertura no nível setorial.

Moreira e Correa (1997) estimaram coeficientes de exportação e de penetração das importações para diversos setores da indústria de transformação brasileira, juntamente com outros indicadores, com o objetivo de fazer uma análise do impacto da abertura comercial sobre a indústria. No que concerne aos coeficientes de abertura comercial, o estudo conclui que a penetração das importações foi bastante significativa na maioria dos setores. Para o total da indústria de transformação, entre 1989 e 1996, teria havido um aumento superior a $200 \%$ deste coeficiente, que se elevou de 4,6 para 14,0.

Ainda segundo este estudo, "a elevação do coeficiente importado foi acompanhada por um aumento também quase que generalizado do coeficiente exportado, em um ritmo, porém, bem mais lento" (p. 74). De acordo com os coeficientes estimados por Moreira e Correa, a participação das vendas externas na produção industrial brasileira subiu de $10,1 \%$ para $14,5 \%$ entre 1989 e 1996 , ou seja, apresentou um aumento de $44 \%$.

Haguenauer, Markwald e Pourchet (1997) reestimam os indicadores de abertura empregando uma metodologia diferente da utilizada por Moreira e Correa (1997) na construção da série de valor da produção em dólar. Os novos indicadores mostram um crescimento menos pronunciado, embora ainda elevado, do coeficiente de penetração das importações (138\% entre 1989 e 1996 para a indústria de transformação). Com relação ao coeficiente de exportação, os valores estimados 
para a indústria de transformação revelam um crescimento de apenas 5,3\% no mesmo período. A despeito das questões metodológicas, os coeficientes de exportação e de penetração das importações construídos nos trabalhos supracitados procuram permitir um melhor entendimento do impacto da abertura comercial sobre a orientação externa da indústria. Porém, como ressaltado por Campa e Goldberg (1997), as conclusões sobre os efeitos de choques externos baseadas apenas nestes indicadores podem ser enganosas, na medida em que não consideram os efeitos via custo de produção, ou seja, via insumos importados.

Do mesmo modo que um choque externo afeta as firmas domésticas via receita (vendas externas e concorrência no mercado doméstico), ele também as afeta via custo de produção. Note-se que os dois efeitos (receita e custo) são antagônicos. Por exemplo, enquanto uma desvalorização cambial tende a afetar as firmas positivamente pelo lado da receita, seu efeito via custo seria negativo. Assim, as conclusões sobre as consequências de tais choques no setor industrial devem considerar ambos os efeitos.

No caso brasileiro recente, este é sem dúvida um efeito importante, dado o crescimento da utilização de insumos importados após a abertura, como será mostrado à frente. Desse modo, seguindo Campa e Goldberg (1997), construiremos neste trabalho duas novas medidas de orientação externa da indústria, que permitirão inferir os prováveis efeitos dos choques externos via insumos importados (custo da produção).

Na próxima seção se expõe a metodologia empregada na construção dos indicadores. A seção 3 apresenta os indicadores e analisa as mudanças na orientação externa da indústria de transformação brasileira. A análise por atividades da indústria de transformação é apresentada na seção 4, enquanto a última seção é reservada às conclusões.

\section{METODOLOGIA}

Utilizaremos em nossa análise quatro indicadores de orientação externa: coeficiente de exportação, coeficiente de penetração das importações, coeficiente de participação de insumos importados e coeficiente de abertura líquida.

O coeficiente de exportação do setor $i\left(\mathrm{CEX}_{i}\right)$ é definido como a participação do valor das exportações do setor $i\left(\mathrm{X}_{i}\right)$ no valor da produção do mesmo setor $\left(V P_{i}\right)$ ou seja,

$$
C E X_{i}=\frac{. X_{i}}{V P} \times 100
$$

Este coeficiente permite analisar a dependência do setor dos mercados doméstico e externo. Assim, quanto maior o coeficiente, maior a dependência do setor no mercado externo e, consequentemente, maior a vulnerabilidade deste a choques externos. 
O coeficiente de penetração das importações (CPIi) é a participação do valor das importações do setor i (Mi) no valor do consumo aparente (valor da produção menos exportações líquidas: $\mathrm{VPi}-\mathrm{Xi}+\mathrm{Mi})$, ou seja,

$$
C P I_{i}=\frac{M_{i}}{V P_{i}-X_{i}+M_{i}} \times 100
$$

Quanto maior for este indicador, maior será a parcela do mercado doméstico atendida por produtos importados e maior será a competição que as firmas domésticas sofrerão por parte dos produtores estrangeiros. Assim, quanto maior o coeficiente de penetração das importações, maiores serão os efeitos de um choque externo sobre o setor.

Diferentemente dos dois indicadores anteriores, o coeficiente de participação de insumos importados (CIIi) mede o impacto de choques externos pelo lado do custo da produção ao invés de via receita. Este coeficiente é definido como a razão entre o valor total dos insumos importados e o valor da produção do setor.

Preferencialmente, deveríamos utilizar o valor dos custos de produção, excluindo-se salários, no denominador. $\mathrm{O}$ uso do valor da produção como base pode ocasionar algum viés na análise, na medida em que mudanças no valor adicionado (margem de lucros e salários) afetariam o índice sem que a participação dos insumos importados no consumo intermediário tenha se alterado. Por outro lado, o emprego do valor da produção facilita a construção do índice de abertura líquida, como ficará claro mais à frente. Ademais, dada a dificuldade para a obtenção do custo de produção em dólares, optamos por usar o valor total da produção.

Outro problema com que nos defrontamos ao calcular o coeficiente de insumos importados refere-se ao valor dos insumos importados por cada setor. Infelizmente, tal valor não é disponível nas estatísticas de comércio exterior do Brasil. Desse modo tivemos que estimá-lo com base na estrutura das matrizes de insumo-produto calculadas pela Fundação IBGE.

Seguindo a metodologia proposta por Campa e Goldberg (1995), assumimos que a distribuição dos insumos importados entre os diversos setores e o consumo final tem a mesma estrutura da matriz de insumo-produto. Ou seja, que a alocação do montante importado de um produto específico entre as diversas atividades produtivas e para consumo final siga o padrão distributivo da oferta interna global de tal produto.

Desse modo, a partir da oferta global (ajustada pela variação do estoque) e do valor dos diversos insumos, classificados a nível 80 (IBGE), consumidos por cada atividade industrial, calculamos o coeficiente insumo-produto $a_{,}$. ou seja, a parcela de insumo $j$ consumida pela atividade $i$. Foram utilizados no cálculo dos coeficientes insumo-produto dos anos de 1989 e 1990 a matriz de insumo produto do IBGE do ano de 1990, para 1991 e 1992 a matriz de 1992, e para os demais anos a matriz de 1994.

Para saber o valor do insumo $j$ importado pelo setor $i$, multiplicamos o coefi- 
ciente insumo-produto $\left(\alpha_{i j}\right)$ pelo valor total das importações do insumo $\left(\mathrm{m}_{j}\right)$. Desse modo, o coeficiente de insumos importados para o setor $i$ é estimado como:

$$
C I I_{i}=\frac{\sum_{i=1}^{n} m_{j} \alpha_{i j}}{V P_{i}} \times 100
$$

Por fim, calculamos o coeficiente de abertura líquida $\left(C A L_{i}\right)$, que é igual à diferença entre os coeficientes de exportação e de insumos importados, ou seja,

$$
C A L_{i}=C E X_{i}-C I I_{i}=\frac{X i-\sum_{i=1}^{n} m_{j} \alpha_{i j}}{V P_{i}} \times 100
$$

Esta medida é um indicador mais preciso da vulnerabilidade de uma indústria a choques externos do que o coeficiente de exportação. Assim, uma indústria com um coeficiente de abertura líquida positivo possui um coeficiente de exportação superior ao coeficiente de insumos importados. Então, o impacto líquido de uma desvalorização cambial seria positivo. No caso contrário, onde o coeficiente de abertura líquida fosse negativo, os efeitos líquidos de uma desvalorização seriam prejudiciais à indústria.

Cabe ressaltar que o indicador de abertura líquida não incorpora todos os efeitos de um choque externo. Desse modo, para um melhor entendimento de tais efeitos sobre uma indústria específica faz-se necessária a utilização conjunta dos quatro indicadores aqui apresentados. Adicionalmente, para resultados mais precisos não se pode desconsiderar as diferenças nas elasticidades de substituição de insumos e da receita de exportação de cada indústria. Estas elasticidades variam entre indústrias e entre insumos, dependendo do conjunto de insumos utilizados e importados por cada setor.

Para o cálculo dos indicadores foram empregados os valores da produção em dólar estimados por Haguenauer, Markwald e Pourchet (1997) e os valores FOB das exportações e importações divulgados pela Secretaria de Comércio Exterior do Ministério do Desenvolvimento, Indústria e Comércio Exterior (Secex/MIDC). A compatibilização da classificação de comércio exterior (NBM/NCM) com as classificações industriais de Produto 80 e de Atividades-Matriz, ambas do IBGE, foi realizada utilizando-se o tradutor do próprio IBGE.

Cabe ressaltar que o procedimento de compatibilização aqui empregado difere do utilizado em Haguenauer, Markwald e Pourchet (1997). Assim os coeficientes de exportação e de penetração das importações produzidos nos dois trabalhos diferem entre si.

São produzidos indicadores para as diferentes atividades da indústria de transformação, classificadas de acordo com a classificação da matriz insumo-produto do IBGE. A análise limita-se ao período compreendido pelos anos de 1989 e 1998, inclusive. A escolha do período inicial baseou-se no processo de abertura comercial 
da economia brasileira, iniciado em 1990. Assim, poderemos empregar os indicadores no acompanhamento das mudanças que ocorreram durante este processo.

\section{INDICADORES DE ORIENTAÇÃO EXTERNA}

O Gráfico 1 apresenta os coeficientes de orientação externa para a indústria brasileira como um todo. É claro no gráfico que durante o processo de abertura comercial houve um aumento significativo dos coeficientes de importação (CPI e CII), comportamento que já era esperado e resulta do elevado grau de fechamento da economia brasileira pré-liberalização.

Embora as importações de bens de consumo duráveis tenham sido as que mais cresceram no período, o aumento das compras de matérias-primas e produtos intermediários também foi significativo. O crescimento da utilização de insumos importados por parte da indústria brasileira é refletido na elevação do coeficiente de participação dos insumos importados (CII) de 3,3 para 5,8 entre 1989 e 1998. Ou seja, um aumento de mais de $70 \%$. Por sua vez, o coeficiente de penetração das importações para a indústria de transformação $(\mathrm{CPI})$ aumentou em pouco mais de $190 \%$ no mesmo período, passando de 4,4 para 13,0.

\section{Gráfico 1: Indicadores de Orientação Externa Indústria de Transformação}

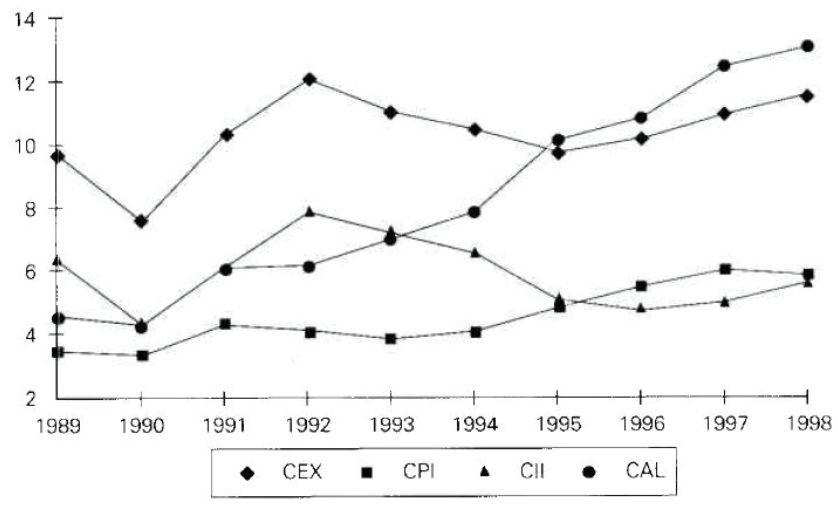

Fonte : Elaborado pelos autores.

Nos últimos anos, o desempenho exportador da indústria brasileira não tem acompanhado a evolução do comércio internacional. A participação das exportações brasileiras no comércio mundial vem caindo desde 1984, sendo que entre 1989 e 1998 esta se reduziu de $1,16 \%$ para $0,85 \%$. No que se refere ao comércio de produtos industrializados neste período, as vendas brasileiras cresceram pouco acima de $50 \%$, cerca da metade do crescimento do comércio mundial de produtos industrializados. Como era de se esperar, este desempenho se reflete no coeficiente de exportação (CEX) e em sua evolução no período.

Em 1998, o coeficiente de exportação da indústria de transformação era de 
11,3 , apenas $18,5 \%$ superior ao coeficiente de 1989 e cerca de $4,8 \%$ inferior ao coeficiente de 1992. Desse modo, tendo em mente as deficiências inerentes a uma análise parcial deste tipo, poderíamos concluir que o mercado externo ainda é encarado marginalmente pelo setor industrial brasileiro e a abertura comercial não reorientou, até o momento, a economia em direção às atividades exportadoras.

No que diz respeito ao período de 1989-96, os resultados aqui apresentados são bastantes similares aos obtidos por Haguenauer, Markwald e Pourchet (1997), o que já era esperado na medida em que ambos os trabalhos se baseiam na mesma base de dados originais. Não obstante, diferem significativamente dos obtidos por Moreira e Correa (1997), que indicam um aumento de $44 \%$ e $237 \%$ nos coeficientes de exportação e de penetração das importações, respectivamente, contra $6,1 \%$ e $140 \%$, respectivamente, de acordo com nossos cálculos. Estas diferenças devemse tanto às diferenças nas séries de produto em dólares, quanto na forma de compatibilização das classificações industriais do IBGE e de comércio exterior (NBM). O gráfico 2 compara os coeficientes de exportação e de penetração das importações da indústria de transformação com a participação das exportações e do consumo aparente totais no PIB, para o período $1989-96 .{ }^{1}$ A despeito do pouco número de observações, os coeficientes de exportação aqui estimados são, aparentemente, bem mais consistentes com a evolução do coeficiente de exportação da economia brasileira como um todo. $\mathrm{O}$ índice de correlação simples entre nossa série e a participação das exportações totais brasileiras no PIB é de $63 \%$, enquanto a série estimada em Moreira e Correa (1997) apresenta uma correlação negativa da ordem de $26 \%$ com esta última. Adicionalmente, o fato de o crescimento do coeficiente de exportação calculado por Moreira e Correia ser praticamente igual ao crescimento das exportações brasileiras de produtos industrializados no período em questão $(43 \%)$ reforça a ideia de os índices apresentados naquele trabalho estarem superdimensionados.

No caso do coeficiente de penetração das importações a diferença entre nossa série e a de Moreira e Correa restringe-se praticamente à magnitude do aumento do coeficiente no período. Como ilustrado pelo gráfico abaixo, a série aqui construída está sempre abaixo da calculada por aqueles autores.

Dada a evolução dos coeficientes de exportação e de participação de insumos importados, o coeficiente de abertura líquida caiu de 6,3, em 1989, para 4,8 em 1996, voltando a crescer para 5,5 em 1998, ou seja, acumulando uma queda de 11,3 \% no período considerado. Em termos de política econômica este comportamento significou uma diminuição do efeito positivo que uma desvalorização cambial teria sobre o ganho dos produtores brasileiros.

\footnotetext{
${ }^{1}$ PIB em dólar calculado pelo Banco Central do Brasil
} 

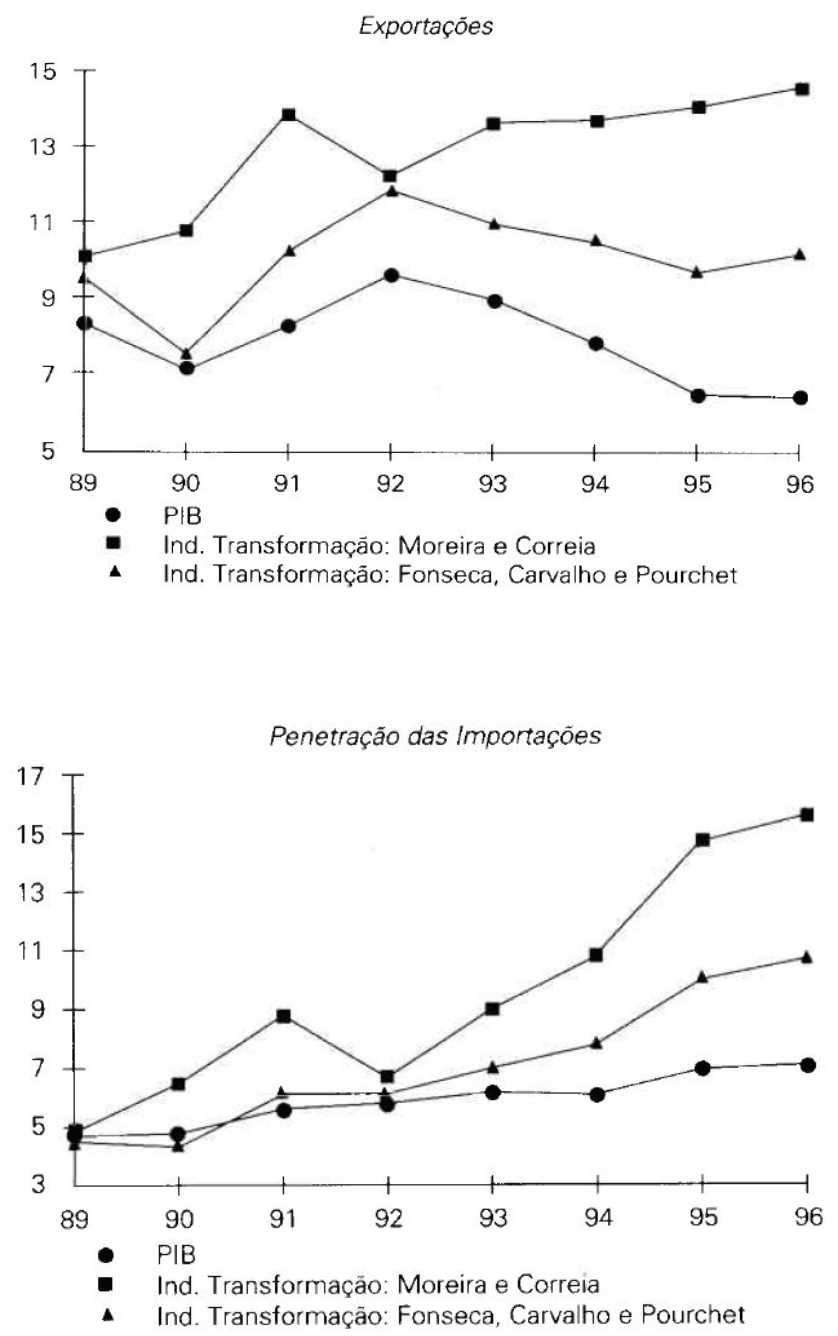

Assim, embora as exportações continuem a responder, em média, por pouco mais de $10 \%$ da receita das firmas industriais brasileiras, o significativo aumento no uso de insumos importados vem compensar, ainda que parcialmente, os efeitos decorrentes dos choques externos. Ou seja, o efeito líquido de um choque externo será de fato a metade do que nos mostraria o coeficiente tradicionalmente utilizado. Por fim, não podemos deixar de considerar que as firmas brasileiras estão ainda sujeitas à concorrência dos produtos estrangeiros, o que faz com que, no caso de um choque do tipo de uma desvalorização cambial, tenhamos um terceiro efeito, favorável às firmas domésticas, via redução da concorrência. Este efeito tem 
sido cada vez mais importante, dado o crescimento ininterrupto do coeficiente de penetração das importações no período considerado.

\section{INDICADORES DE ORIENTAÇÃO EXTERNA A NÍVEL SETORIAL}

Analisando a evolução dos indicadores de abertura setorialmente, nota-se que o impacto da abertura foi diferenciado. Ou seja, há indícios de ter ocorrido uma mudança na estrutura da orientação externa da economia brasileira, ainda que não muito significativa. Esta mudança tem sido mais sensível pelo lado das importações. Como forma de verificar a ocorrência ou não de mudanças na estrutura da orientação externa setorial, estimamos coeficientes de correlação simples entre as estruturas de cada um dos quatro indicadores de cada ano considerado. As matrizes de correlação simples são apresentadas na Tabela 1. Assim, quanto maior for a correlação simples entre as estruturas dos diferentes anos, menor será a mudança na estrutura de orientação externa da economia.

Ao que se pode observar, a correlação entre os anos mantém-se elevada. Contudo, os coeficientes de correlação diminuem à medida que aumentamos o intervalo entre os anos. Ou seja, há indícios de mudanças estruturais, embora pequenas. O maior impacto estrutural ocorreu no coeficiente de insumos importados. Esta é uma mudança esperada na medida em que setores que tinham o acesso ao mercado internacional vedado passam a incorporar insumos importados em seus processos de produção.

O acompanhamento da evolução dos coeficientes de correlação no decorrer dos anos (veja, por exemplo, a coluna 1 de cada matriz da Tabela 1) sugere que as mudanças estruturais mais significativas ocorreram nos anos de 1992 e 1993, período de consolidação dos cortes tarifários. Ou seja, a liberalização comercial teve pouco impacto em seus anos iniciais, mas gerou mudanças significativas, sobretudo na estrutura de importações, em 1992 e 1993. A partir de então, o processo de mudança estrutural parece ter arrefecido, voltando com maior intensidade em 1997, dando sinais de que a indústria de transformação brasileira ainda não encontrou sua nova estrutura de orientação externa. 
Tabela 1: Coeficientes de Correlação Simples entre

as Estruturas dos Indicadores de Orientação Externa

\begin{tabular}{|c|c|c|c|c|c|c|c|c|c|c|}
\hline \multicolumn{11}{|c|}{ SÉRIE COEFICIENTES DE EXPORTAÇÃO } \\
\hline & 89 & 90 & 91 & 92 & 93 & 94 & 95 & 96 & 97 & 98 \\
\hline 89 & 1,00 & & & & & & & & & \\
\hline 90 & 0,96 & 1,00 & & & & & & & & \\
\hline 91 & 0,96 & 0,96 & 1,00 & & & & & & & \\
\hline 92 & 0,87 & 0,94 & 0,94 & 1,00 & & & & & & \\
\hline 93 & 0,84 & 0,93 & 0,91 & 0,99 & 1,00 & & & & & \\
\hline 94 & 0,95 & 0,98 & 0,96 & 0,95 & 0,96 & 1,00 & & & & \\
\hline 95 & 0,85 & 0,93 & 0,88 & 0,90 & 0,95 & 0,95 & 1,00 & & & \\
\hline 96 & 0,82 & 0,93 & 0,84 & 0,93 & 0,96 & 0,94 & 0,97 & 1,00 & & \\
\hline 97 & 0,89 & 0,95 & 0,91 & 0,94 & 0,97 & 0,98 & 0,97 & 0,98 & 1,00 & \\
\hline 98 & 0,82 & 0,89 & 0,88 & 0,93 & 0,96 & 0,93 & 0,95 & 0,94 & 0,97 & 1,00 \\
\hline
\end{tabular}

SÉRIE COEFICIENTES DE PENTRAÇÃO DAS IMPORTAÇÕES

\begin{tabular}{|c|c|c|c|c|c|c|c|c|c|c|}
\hline & 89 & 90 & 91 & 92 & 93 & 94 & 95 & 96 & 97 & 98 \\
\hline 89 & 1,00 & & & & & & & & & \\
\hline 90 & 0,97 & 1,00 & & & & & & & & \\
\hline 91 & 0,95 & 0,98 & 1,00 & & & & & & & \\
\hline 92 & 0,91 & 0,92 & 0,96 & 1,00 & & & & & & \\
\hline 93 & 0,87 & 0,87 & 0,93 & 0,98 & 1,00 & & & & & \\
\hline 94 & 0,85 & 0,85 & 0,90 & 0,96 & 0,98 & 1,00 & & & & \\
\hline 95 & 0,84 & 0,85 & 0,91 & 0,95 & 0,98 & 0,98 & 1,00 & & & \\
\hline 96 & 0,83 & 0,85 & 0,91 & 0,96 & 0,97 & 0,98 & 0,98 & 1,00 & & \\
\hline 97 & 0,79 & 0,79 & 0,87 & 0,94 & 0,96 & 0,98 & 0,97 & 0,99 & 1,00 & \\
\hline 98 & 0,76 & 0,77 & 0,85 & 0,93 & 0,95 & 0,97 & 0,96 & 0,96 & 0,98 & 1,00 \\
\hline
\end{tabular}

SÉRIE COEFICIENTES DE PARTICIPAÇÃO DOS INSUMOS IMPORTADOS

\begin{tabular}{|c|c|c|c|c|c|c|c|c|c|c|}
\hline & 89 & 90 & 91 & 92 & 93 & 94 & 95 & 96 & 97 & 98 \\
\hline 89 & 1,00 & & & & & & & & & \\
\hline 90 & 0,96 & 1,00 & & & & & & & & \\
\hline 91 & 0,97 & 0,95 & 1,00 & & & & & & & \\
\hline 92 & 0,88 & 0,94 & 0,94 & 1,00 & & & & & & \\
\hline 93 & 0,85 & 0,93 & 0,91 & 0,98 & 1,00 & & & & & \\
\hline 94 & 0,95 & 0,97 & 0,97 & 0,95 & 0,96 & 1,00 & & & & \\
\hline 95 & 0,86 & 0,93 & 0,89 & 0,90 & 0,95 & 0,96 & 1,00 & & & \\
\hline 96 & 0,84 & 0,93 & 0,86 & 0,93 & 0,97 & 0,95 & 0,97 & 1,00 & & \\
\hline 97 & 0,89 & 0,95 & 0,92 & 0,94 & 0,97 & 0,98 & 0,98 & 0,98 & 1,00 & \\
\hline 98 & 0,84 & 0,90 & 0,89 & 0,93 & 0,96 & 0,94 & 0,97 & 0,95 & 0,98 & 1,00 \\
\hline
\end{tabular}

Fonte: Elaborada pelos autores. 
A Tabela 2 apresenta os coeficientes setoriais médios para os triénios 1989-91 e 1996-98. Analisando-se o desempenho das 28 atividades industriais no que concerne ao coeficiente de exportação, vê-se que cinco atividades apresentaram queda no coeficiente entre os triénios em questão. Destas, chama atenção o desempenho da atividade Siderurgia, cujo coeficiente médio se reduz em $35 \%$, caindo de 21,0 para 13,7 . Em seguida, no grupo de pior desempenho, temos Refino do Petróleo, com queda de $31 \%$, e Outros Produtos Alimentares (queda de $20 \%$ ).

Entre as atividades com maior crescimento na orientação externa "bruta" (medida pelo coeficiente de exportação), temos: Açúcar, Madeira e Mobiliário, Material Elétrico, Máquinas e Tratores, e Calçados. ${ }^{2}$ Durante este período, os coeficientes das atividades Calçados e Óleos Vegetais ultrapassaram 50,0, passando este setor a integrar, juntamente com Café, o seleto grupo de atividades cujas vendas externas respondem por mais da metade da receita auferida pelo setor.

Note-se que 15 atividades industriais $(54 \%$ do total de atividades consideradas) apresentavam um coeficiente de exportação superior à média da indústria de transformação no triénio 1996-98. No outro extremo temos Laticínios, Artigos de Vestuário, Farmacêutica e Perfumaria e Minerais Não-Metálicos, com coeficientes inferiores a 3,0, ou seja, atividades voltadas primordialmente para o mercado doméstico. Ajustando-se o coeficiente de exportação pelo de participação de insumos importados, ou seja, utilizando-se o coeficiente de abertura líquida, mudam-se consideravelmente algumas das conclusões anteriores. No que concerne aos setores mais abertos, não há surpresas. As cincos atividades industriais listadas anteriormente mantêm suas posições relativas, embora os coeficientes sejam menores, sobretudo no caso da atividade Metalurgia de Não-Ferrosos, cujo coeficiente se reduz de 28,4 para 18,2 .

As diferenças entre os coeficientes de abertura líquida e "bruta" são mais marcantes entre as atividades com coeficientes baixos, ou seja, aquelas tidas como menos abertas ao comércio internacional. Dos seis setores com menores coeficientes de exportação, apenas três (Artigos de Vestuário, Artigos de Plástico e Refino do Petróleo) permanecem entre os de menores coeficientes de abertura líquida.

A Tabela 3 apresenta as atividades industriais em ordem decrescente do coeficiente médio de abertura líquida do triénio 1996-98. É possível, então, agrupar as indústrias de acordo com seu grau de vulnerabilidade a choques externos.

\footnotetext{
${ }^{2} \mathrm{Na}$ verdade, Laticínios foi a atividade com a maior variação relativa do coeficiente de exportação. Porém, isto deveu-se ao fato de os valores absolutos dos coeficientes serem próximos de zero.
} 
Tabela 2: Coeficientes de Orientação Externa

da Indústria de Transformação Brasileira

\begin{tabular}{|c|c|c|c|c|c|c|c|c|}
\hline \multirow[t]{2}{*}{ Atividades - Matriz } & \multicolumn{2}{|c|}{ CEX } & \multicolumn{2}{|c|}{$\mathrm{CPI}$} & \multicolumn{2}{|c|}{$\mathrm{Cll}$} & \multicolumn{2}{|c|}{$\mathrm{CAL}$} \\
\hline & $89-91$ & $96-98$ & $89-91$ & $96-98$ & $89-91$ & $96-98$ & $89-91$ & $96-98$ \\
\hline Indústria de Transformação & 9,1 & 10,8 & 4,9 & 12,1 & 3,6 & 5,7 & 5,5 & 5,1 \\
\hline Minerais Não-Metálicos & 1,8 & 2,8 & 0,9 & 1,9 & 1,7 & 2,1 & 0,1 & 0,7 \\
\hline Siderurgia & 21,0 & 13,7 & 2,4 & 2,8 & 4,1 & 5,0 & 16,8 & 8,7 \\
\hline Metalurgia Não-Ferrosos & 24,6 & 28,4 & 8,9 & 16,8 & 5,7 & 10,2 & 18,9 & 18,2 \\
\hline $\begin{array}{l}\text { Outros Produtos Metalúr- } \\
\text { gicos }\end{array}$ & 5,3 & 6,6 & 2,1 & 7,9 & 3,1 & 5,5 & 2,2 & 1,1 \\
\hline Máquinas e Tratores & 5,2 & 9,7 & 8,7 & 25,2 & 1,6 & 3,7 & 3,6 & 6,0 \\
\hline Material Elétrico & 9,4 & 17,9 & 9,6 & 31,1 & 3,3 & 11,8 & 6,1 & 6,1 \\
\hline Equipamentos Eletrônicos & 7,2 & 13,0 & 14,5 & 48,3 & 4,0 & 16,6 & 3,2 & $-3,5$ \\
\hline Automóveis, Cam. e Ônibus & 9,4 & 12,3 & 0,7 & 14,6 & 3,0 & 7,2 & 6,3 & 5,0 \\
\hline Outros Veículos e Peças & 15,5 & 18,3 & 9,0 & 19,6 & 2,7 & 6,2 & 12,8 & 12,1 \\
\hline Madeira e M obiliário & 3,9 & 8,0 & 0,3 & 1,5 & 0,7 & 1,3 & 3,2 & 6,7 \\
\hline Celulose, Papel e Gráfica & 8,3 & 11,1 & 2,6 & 7,7 & 2,0 & 4,9 & 6,2 & 6,2 \\
\hline Borracha & 9,0 & 9,8 & 7,1 & 11,0 & 3,8 & 6,3 & 5,2 & 3,4 \\
\hline Elementos Químicos & 6,8 & 11,7 & 16,3 & 24,2 & 3,7 & 6,7 & 3,1 & 5,0 \\
\hline Refino do Petróleo & 4,9 & 3,3 & 3,9 & 9,9 & 12,7 & 10,2 & $-7,8$ & $-6,9$ \\
\hline Químicos Diversos & 2,8 & 5,0 & 6,3 & 12,1 & 5,3 & 8,8 & $-2,4$ & $-3,7$ \\
\hline Farmacêutica e Perfumaria & 1,6 & 2,2 & 6,2 & 10,7 & 2,1 & 2,4 & $-0,5$ & $-0,3$ \\
\hline Artigos de Plástico & 1,9 & 3,1 & 2,1 & 8,4 & 2,6 & 7,0 & $-0,8$ & $-3,9$ \\
\hline Têxtil & 8,8 & 11,1 & 3,5 & 17,9 & 3,3 & 16,0 & 5,5 & $-4,9$ \\
\hline Artigos de Vestuário & 1,2 & 1,9 & 0,4 & 4,7 & 0,7 & 4,8 & 0,5 & $-2,9$ \\
\hline Calçados & 34,2 & 62,4 & 7,5 & 20,6 & 2,7 & 6,8 & 31,4 & 55,6 \\
\hline Café & 68,3 & 65,1 & 0,0 & 0,2 & 0,2 & 0,4 & 68,1 & 64,8 \\
\hline Benef ic. Produtos Vegetais & 15,3 & 14,4 & 2,4 & 4,3 & 2,3 & 4,6 & 12,9 & 9,8 \\
\hline Abate de Animais & 9,5 & 16,1 & 3,9 & 3,0 & 1,1 & 1,5 & 8,4 & 14,5 \\
\hline Laticínios & 0,0 & 0,1 & 3,2 & 3,8 & 0,8 & 1,0 & $-0,8$ & $-0,9$ \\
\hline Açúcar & 16,3 & 45,2 & 0,0 & 0,2 & 1,6 & 3,5 & 14,7 & 41,8 \\
\hline Óleos Vegetais & 36,1 & 51,2 & 2,6 & 11,9 & 1,5 & 7,0 & 34,5 & 44,2 \\
\hline $\begin{array}{l}\text { Outros Produtos } \\
\text { Alimentares }\end{array}$ & 4,8 & 3,8 & 2,3 & 4,1 & 1,3 & 2,0 & 3,6 & 1,8 \\
\hline Indústrias Diversas & 7,8 & 9,0 & 12,5 & 23,7 & 1,5 & 3,0 & 6,2 & 6,0 \\
\hline
\end{tabular}

Fonte. Elaborado pelos autores.

Legenda: CEX - Coef. de Exportação; CPI - Coef. de Penetr . das Importações; CII - Coef de Part de Insumos Importados; CAL - Coef. de Abertura Líquida. 
Tabela 3: Coeficientes de Abertura Líquida Indústria de Transformação Brasileira

\begin{tabular}{|c|c|c|}
\hline \multirow[t]{2}{*}{ Atividades - Matriz } & \multicolumn{2}{|c|}{ Triênios } \\
\hline & $1989-91$ & $1996-98$ \\
\hline Indústria de Transformação & 5,5 & 5,1 \\
\hline Café & 68,1 & 64,8 \\
\hline Calçados & 31,4 & 55,6 \\
\hline Óleos Vegetais & 34,5 & 44,2 \\
\hline Açúcar & 14,7 & 41,8 \\
\hline Metalurgia Não-Ferrosos & 18,9 & 18,2 \\
\hline Abate de Animais & 8,4 & 14,5 \\
\hline Outros Veículos e Peças & 12,8 & 12,1 \\
\hline Benefic. Produtos Vegetais & 12,9 & 9,8 \\
\hline Siderurgia & 16,8 & 8,7 \\
\hline Madeira e Mobiliário & 3,2 & 6,7 \\
\hline Celulose, Papel e Gráfica & 6,2 & 6,2 \\
\hline Material Elétrico & 6,1 & 6,1 \\
\hline Indústrias Diversas & 6,2 & 6,0 \\
\hline Máquinas e Tratores & 3,6 & 6,0 \\
\hline Automóveis, Caminhões e Ônibus & 6,3 & 5,0 \\
\hline Elementos Químicos & 3,1 & 5,0 \\
\hline Borracha & 5,2 & 3,4 \\
\hline Outros Produtos Alimentares & 3,6 & 1,8 \\
\hline Outros Produtos Metalúrgicos & 2,2 & 1,1 \\
\hline Minerais Não-Metálicos & 0,1 & 0,7 \\
\hline Farmacêutica e Perfumaria & $-0,5$ & $-0,3$ \\
\hline Laticínios & $-0,8$ & $-0,9$ \\
\hline Artigos de Vestuár io & 0,5 & $-2,9$ \\
\hline Equipamentos Eletrônicos & 3,2 & $-3,5$ \\
\hline Químicos Diversos & $-2,4$ & $-3,7$ \\
\hline Artigos de Plástico & $-0,8$ & $-3,9$ \\
\hline Têxtil & 5,5 & $-4,9$ \\
\hline Refino do Petróleo & $-7,8$ & $-6,9$ \\
\hline
\end{tabular}

Fonte: Elaborada pelos autores.

No primeiro grupo encontram-se os setores exportadores tradicionais que possuem coeficientes superiores a 15,0. Estes são setores que certamente seriam beneficiados com um choque externo do tipo de uma desvalorização cambial. Em seguida temos aquelas atividades com coeficientes entre 2,0 e 15,0. Estes são setores com uma receita líquida em divisas externas significativa e que poderão vir a se beneficiar de uma desvalorização da moeda doméstica.

O grupo seguinte é composto por setores com coeficientes próximos de zero, ou seja, com pequeno impacto líquido decorrente de choques externos. Por último, 
temos aquelas atividades que, devido ao volume de insumos importados emprega dos na produção, tendem a sofrer os efeitos provenientes de choques externos de maneira reversa. Desse modo, as firmas correspondentes a estas atividades perderiam com uma desvalorização cambial.

Dentre estas indústrias chama atenção o desempenho das indústrias têxtil e produtoras de equipamentos eletrônicos, que detinham coeficientes médio positivos e acima de 2,0 no triénio 1989-91, mas que com a liberalização comercial aumentaram o emprego de insumos importados de tal modo que os coeficientes tornaramse significativamente negativos.

Para uma melhor compreensão do efeito de um choque externo sobre as diferentes atividades industriais brasileiras, faz-se necessário, ainda, considerar o impacto via penetração das importações no mercado doméstico. O efeito negativo que uma desvalorização cambial teria sobre a rentabilidade dos setores do último grupo da Tabela 3 podem ser mais do que compensados via redução da competição com importados. Assim, quanto maior o coeficiente de penetração das importações do setor, maiores as possibilidades de se obter um ganho com uma desvalorização da moeda doméstica, mesmo que o coeficiente de abertura líquida seja negativo.

Entre as atividades industriais brasileiras com maior penetração das importações em seus mercados temos Equipamentos Eletrônicos, Material Elétrico, Máquinas e Tratores, Elementos Químicos, Indústrias Diversas e Calçados, todos com coeficiente acima de $20 \%$. No outro extremo, ou seja, dentre os setores com os menores coeficientes de penetração das importações (abaixo de 2,0), temos: Café, Açúcar, Madeira e Mobiliário e Minerais Não-Metálicos (veja Tabela 2). Note-se, contudo, que estes setores apresentaram um crescimento acima de $100 \%$ em seus coeficientes médios entre os triênios de 1989-91 e 1996-98.

De fato, com exceção de Abates de Animais, em todas as demais atividades constata-se crescimento no coeficiente de penetração das importações entre os triênios considerados. ${ }^{1}$ Desse modo, algumas atividades, ainda que apresentem coeficientes menores, foram relativamente mais afetadas pelo processo de abertura da economia. Dentre estas, a atividade Automóveis, Caminhões e Ônibus foi a mais afetada por este processo. Seu coeficiente de penetração das importações apresentou uma taxa de crescimento média no período de mais de $95 \%$ ao ano, saltando de 0,05 em 1989 para 20,6 em 1998.

A Tabela 4 lista as diversas atividades industriais em ordem decrescente da taxa de variação média anual no período. Excluindo-se as atividades Café, Açúcar e Madeira e Mobiliário, que apesar do elevado crescimento relativo são atividades com baixos coeficientes de penetração, vemos que Artigos de Vestuário e Têxtil completam o grupo das atividades mais afetadas. Os coeficientes de penetração das importações desses segmentos cresceram, entre 1989 e 1998, a uma taxa anual média de $42 \%$ e $23 \%$, respectivamente.

\footnotetext{
${ }^{1}$ Note-se que considerando a evolução ponta a ponta entre 1989 e 1998, Laticínios também apresentaram redução no coeficiente de penetração das importações.
} 
Tabela 4: Coeficiente de Penetração das Importações Indústria de Transformação Brasileira

\begin{tabular}{|c|c|c|}
\hline Atividades - Matriz & $\begin{array}{c}\text { Variação Anual Média } \\
\text { 1989-98 }\end{array}$ & $\begin{array}{c}\text { Coeficiente Médio } \\
\text { do Triênio 96-98 }\end{array}$ \\
\hline Indústria de Transformação & $13 \%$ & 12,1 \\
\hline Automóveis, Caminhões e Ônibus & $95 \%$ & 14,6 \\
\hline Café & $74 \%$ & 0,2 \\
\hline Artigos de Vestuário & $42 \%$ & 4,7 \\
\hline Açúcar & $42 \%$ & 0,2 \\
\hline Madeira e Mobiliário & $24 \%$ & 1,5 \\
\hline Têxtil & $23 \%$ & 17,9 \\
\hline Outros Produtos Metalúrgicos & $22 \%$ & 7,9 \\
\hline Artigos de Plástico & $21 \%$ & 8,4 \\
\hline Máquinas e Tratores & $19 \%$ & 25,2 \\
\hline Material Elétrico & $17 \%$ & 31,1 \\
\hline Equipamentos Eletrônicos & $17 \%$ & 48,3 \\
\hline Calçados & $15 \%$ & 20,6 \\
\hline Celulose, Papel e Gráfica & $14 \%$ & 7,7 \\
\hline Outros Veículos e Peças & $13 \%$ & 19,6 \\
\hline Óleos Vegetais & $13 \%$ & 11,9 \\
\hline Benefic. Produtos Vegetais & $12 \%$ & 4,3 \\
\hline Refino do Petróleo & $11 \%$ & 9,9 \\
\hline Minerais Não-Metálicos & $9 \%$ & 1,9 \\
\hline Indústrias Diversas & $8 \%$ & 23,7 \\
\hline Metalurgia Não-Ferrosos & $8 \%$ & 16,8 \\
\hline Químicos Diversos & $8 \%$ & 12,1 \\
\hline Farmacêutica e Perfumaria & $7 \%$ & 10,7 \\
\hline Borracha & $6 \%$ & 11,0 \\
\hline Elementos Químicos & $6 \%$ & 24,2 \\
\hline Outros Produtos Alimentares & $6 \%$ & 4,1 \\
\hline Siderurgia & $4 \%$ & 2,8 \\
\hline Laticínios & $-1 \%$ & 3,8 \\
\hline Abate de Animais & $-7 \%$ & 3,0 \\
\hline
\end{tabular}

Fonte: Elaborada pelos autores.

Outras atividades significativamente afetadas foram: Outros Produtos Metalúrgicos, Artigos de Plástico, Material Elétrico, Equipamentos Eletrônicos e Calçados. Todas com taxas médias de crescimento do coeficiente de penetração das importações superiores a 15,0 ao ano.

Assim, analisando-se uma vez mais as atividades com coeficiente de abertura líquida negativo, nota-se que com relação a Equipamentos Eletrônicos o efeito final de um choque externo (do tipo de uma desvalorização cambial) deverá ser positivo. Isto se deve ao elevado coeficiente de penetração das importações desta atividade (48,3 no triênio 1996-98), o maior dentre as atividades da indústria de transformação. 
Outras indústrias com coeficiente de abertura líquida negativo, mas com coeficiente de penetração das importações relativamente elevado são: Têxtil e Químicos Diversos.

\section{CONCLUSÕES}

O objetivo deste trabalho foi construir e analisar indicadores de orientação externa da economia brasileira que permitissem um melhor entendimento das mudanças na orientação externa brasileira pós-liberalização e dos efeitos dos choques externos, levando-se em conta o custo da produção via insumos importados. A ideia de construir estes indicadores partiu da premissa de que um choque externo afeta as firmas domésticas via receita (vendas externas e concorrência no mercado doméstico) e via custo de produção (utilização de insumos importados).

Assim, enquanto uma desvalorização cambial afeta positivamente as firmas pelo lado da receita, pelo lado do custo esta desvalorização teria um efeito negativo. Qualquer avaliação do impacto de choques externos deve, portanto, considerar ambos os efeitos. Isto é muito importante para o caso brasileiro recente, na medida em que se constata um crescimento significativo dos insumos importados no período pós-abertura.

A análise aqui desenvolvida mostrou que a estrutura da orientação externa brasileira vem se modificando nos últimos anos e que estas modificações vêm se dando primordialmente pelo lado das compras externas. Nos últimos anos houve um crescimento significativo na penetração dos produtos importados no mercado brasileiro, tanto para consumo final quanto intermediário, da indústria de transformação. Ademais, este crescimento não foi uniforme entre as diversas atividades, gerando mudanças na estrutura de orientação externa brasileira, principalmente no que concerne às importações de produtos intermediários.

Por outro lado, o coeficiente de exportação demonstrou relativa estabilidade no período pós-liberalização, refletindo o enfoque marginal dado ao mercado externo pelo setor industrial brasileiro, enfoque este que a abertura comercial ainda não conseguiu modificar. Assim, aparentemente, as exportações brasileiras de manufaturados ainda não foram significativamente afetadas pelo processo de modernização da indústria iniciado nos últimos anos.

Adicionalmente, este estudo indica que, em termos gerais, houve uma redução do coeficiente de abertura líquida da indústria de transformação de $11,3 \%$ entre 1989 e 1998. Desse modo, para efeitos de política econômica, houve uma diminuição significativa do efeito positivo que uma desvalorização cambial provocaria sobre o ganho dos produtores domésticos.

Em termos estruturais, há ainda indícios de que a liberalização comercial teve pouco impacto em seus anos iniciais, e gerou mudanças significativas, sobretudo na estrutura de importações, em 1992 e 1993. A partir de então, o processo de mudança estrutural parece ter arrefecido, voltando com maior intensidade em 1997, dando sinais de que a indústria de transformação brasileira ainda não encontrou sua nova estrutura de orientação externa.

A análise setorial dos coeficientes de orientação externa veio confirmar que as 
atividades industriais com maior grau de abertura, ou melhor, que destinam uma parcela significativa de sua produção ao mercado externo, são aquelas tradicional mente exportadoras: Café, Calçados, Óleos Vegetais e Açúcar. Mesmo após considerar o consumo de insumos importados, estas atividades continuam bastante vulneráveis a choques externos, ou seja, com coeficientes de abertura líquida acima de 40,0 . Estes são setores que certamente seriam beneficiados por um choque externo do tipo de uma desvalorização cambial.

No outro extremo, temos as atividades Refino do Petróleo, Têxtil, Artigos de Plástico, Químicos Diversos, Equipamentos Eletrônicos e Artigos de Vestuário, que possuem coeficiente de abertura líquida negativo. As firmas localizadas nestes setores tendem a sofrer os efeitos provenientes de choques externos de maneira reversa, ou seja, são firmas que podem vir a ser prejudicadas por uma desvalorização cambial. No entanto, para uma melhor compreensão do efeito final de um choque externo sobre as diferentes atividades industriais brasileiras, faz-se necessário ainda contabilizar o impacto via concorrência dos produtos estrangeiros no mercado doméstico. No caso do setor produtor de equipamentos eletrônicos, por exemplo, ainda que o coeficiente de abertura líquida seja negativo, há uma forte penetração das importações no mercado doméstico. Desse modo, dado seu efeito redutor da competitividade dos produtos importados, o efeito final de uma desvalorização deverá ser positivo.

Por fim, cabe identificar as atividades relativamente mais afetadas pela abertura comercial. Com relação ao aumento da competição com produtos importados, as mais afetadas foram Automóveis, Caminhões e Ônibus, Artigos de Vestuário, Têxtil e Produtos Plásticos. Por outro lado, praticamente todas as atividades se beneficiaram via importação de insumos. Destas, as que mais se utilizaram desta nova possibilidade foram: Artigos de Vestuário, Têxtil, Óleos Vegetais, Equipamentos Eletrônicos e Material Elétrico. Com relação às exportações, deve-se destacar o desempenho das atividades Madeira e Mobiliário e Material Elétrico, setores exportadores não-tradicionais, que praticamente dobraram o coeficiente de exportação entre os triênios de 1989-91 e 1996-98.

\section{REFERÊNCIAS BIBLIOGRÁFICAS}

CAMPA, J. e L. S. GOLDBERG, 1997, “The evolving external orientation of Manufacturing: A profile of four countries, "FRBNY Economic Policy Review, July.

FONSECA, R, 1996, "Product innovation in Brazilian autos", University of California at Berkeley, Department of Economics, unpublished Ph.D. Dissertation.

HAGUENAUER, L.; R. MARKWALD e H. POURCHET, 1997, "Estimativas do valor da produção industrial e elaboração de coeficientes de exportação e importação da indústria brasileira (1985/96)". FUNCEX-IPEA, mimeo, novembro.

HAY, D. A., 1997, "The post 1990 Brazilian trade liberalization and the performance of large manufacturing firms: productivity, market share and profits,” IPEA Texto para Discussão 523, outubro.

MOREIRA, M.M. e P.G. CORREA, 1997, "Abertura comercial e indústria: o que se pode esperar e o que se vem obtendo," Revista de Economia Política, vol. 17, 2 (66), abril-junho. 